\title{
Colored Food Emulsions-Implications of Pigment Addition on the Rheological Behavior and Microstructure
}

\author{
Ana Paula Batista - Anabela Raymundo • Isabel Sousa • \\ José Empis • José Maria Franco
}

(C) Springer Science+Business Media, Inc. 2006

\begin{abstract}
Coloring foods with natural pigments enables the development of attractive products with nutritional advantages. The overall objective of this work was to study the consequences of adding the pigments lutein (lipophylic) and phycocyanin (hydrophilic) on the rheological behavior of oil-in-water food emulsions stabilized by pea protein isolate. The emulsions were characterized in terms of their linear viscoelasticity, and of their steady and transient flow behaviors. The rheological tests were monitored by using a microscope (optical analysis system) coupled to a controlled stress rheometer. Upon lutein incorporation, the emulsions became less stable, presenting lower rheological
\end{abstract}

\author{
A. P. Batista $(\bowtie) \cdot$ A. Raymundo \\ Centro de Investigação de Eng. ${ }^{\text {a }}$ Alimentar e Biotecnologia, \\ Instituto Piaget - I.S.E.I.T. de Almada, \\ Quinta da Arreinela de Cima, \\ 2800-305 Almada, Portugal \\ e-mail: pbatista@almada.ipiaget.org \\ A. Raymundo \\ e-mail: araymundo@almada.ipiaget.org \\ I. Sousa \\ Secção de Ciência e Tecnologia dos Alimentos, DAIAT, \\ Instituto Superior de Agronomia, \\ Tapada da Ajuda, 1349-017 Lisboa, Portugal \\ e-mail: isabelsousa@isa.utl.pt \\ J. Empis \\ IBB-Institute for Biotechnology and Bioengineering, \\ Centre for Biological and Chemical Engineering, \\ Instituto Superior Técnico Av. Rovisco Pais, \\ 1049-001 Lisboa, Portugal \\ e-mail: jempis@ist.utl.pt \\ J. M. Franco \\ Dpto. Ingeníeria Química. Campus del Cármen, \\ Universidad de Huelva, Fac. Ciências Experimentales, \\ 21071 Huelva, Spain \\ e-mail: franco@uhu.es
}

function values than the control emulsion (without pigment addition). On the other hand, phycocianin addition resulted in a significant reinforcement of emulsion structure, a higher resistance to structural breakdown becoming evident. An emulsion containing both pigments, in the same proportion, presented an intermediate rheological behavior resulting from a combination of the effects observed for the emulsions containing each of them.

Keywords Emulsions · Lutein · Phycocyanin .

Viscoelasticity $\cdot$ Rheology

\section{Introduction}

Color is an important quality attribute of food products, being a determinant of its acceptability. The attainment of the adequate color, according to the consumer expectations on the product, is usually accomplished through the use of coloring. In the food industry, these compounds are used in colorless food products as well as to compensate for color lost as a result of processing conditions (e.g., high temperature and pressure). The current trend is to replace synthetic colorings by natural pigments, such as carotenoids and anthocyanins, phytochemicals for many of which nutraceutical effects have been claimed, including antioxidant activity. ${ }^{1,2}$ Therefore, use of natural coloring can be an interesting tool in the development of new foods, in response to increasing consumer demand for more natural food products presenting health benefits.

Most food products are complex colloidal systems resulting from the combination of numerous food components (e.g., proteins, carbohydrates, and lipids) organized and arranged in very complex internal microstructures with various types of assemblies such as dispersions, emulsions, 
foams, gels, etc. ${ }^{3}$ The overall stability and structural properties of colloidal systems depends not only on the functional properties of the individual ingredients, but also on the nature and strength of the interactions between them. ${ }^{4,5}$

Therefore, the introduction of natural pigments in colloidal food systems, such as oil-in-water emulsions, can also change the microstructure and perceived texture, because the emulsions' behavior during its production, processing, and storage is highly dependent on composition. ${ }^{6}$ The physical properties of the aqueous and fat phases may be modified according to the nature and polarnonpolar affinities of the pigments, and if they possess surface-active properties, pigment molecules may be preferentially located at the interface. The interactions of the pigments with emulsifier and stabilizing agents at the surface of the emulsion droplets as well as in the aqueous medium among the droplets ${ }^{7,8}$ can contribute to a reinforcement of the emulsion structure through the formation of physical entanglements, ${ }^{9-11}$ but if these constituents are incompatible the emulsion becomes less stable.

Lutein is an orange-colored liposoluble xantophyll, with two hydroxyl groups in the conjugated polyene chain, present in fruits and vegetables. The functional properties of this pigment are mainly recognized as providing diminished incidence of eye diseases such as age-related macular degeneration and cataracts, and certain types of cancer. ${ }^{12}$ Recent studies have investigated the stability of emulsions and microemulsions enriched with carotenoids, such as lycopene, ${ }^{13,14}$ astaxanthin, ${ }^{15}$ and lutein. ${ }^{16,17}$ These systems can be used as vehicles of nutraceutical carotenoids in food applications. All carotenoid molecules present a hydrophobic character, and are consequently dissolved in the nonpolar oil phase of the emulsion. Nevertheless, it should be considered that the presence of polar hydroxyl groups in the end of some carotenoid molecules, such as lutein and astaxanthin, can provide a certain polar character ${ }^{18,19}$ and potential interfacial activity, as well as the ability to bind with proteins through intermolecular hydrogen bonds. ${ }^{20,21}$

Phycocyanin is a blue photosynthetic pigment extracted from cyanobacteria with reported antioxidant activity in vitro. ${ }^{22}$ It is a hydrophilic phycobiliprotein composed by an apoprotein linked to colored prosthetic groups (tetrapyrrolic chromophores). Biliproteins are highly soluble in water, which renders their application in nonpolar systems difficult. To overcome this limitation, some experimental studies have tested the incorporation of these compounds in multiphase systems, such as reverse micelles and microemulsions. ${ }^{23,24}$ However, because of its protein nature, it is possible that phycocyanin presents some surface activity. ${ }^{25}$

Proteins are widely used as emulsifiers in the food industry. The presence of polar and nonpolar amino acids along their polypeptide backbone provides simultaneous affinity to the aqueous and oil phases, enabling them to adsorb at the interface. The formation of a protein layer provides protection from droplet aggregation by a combination of electrostatic and stereochemical interactions. ${ }^{26}$ Proteins may also act as emulsion stabilizers by increasing the viscosity of the continuous phase, and by preventing droplets' aggregation in a mechanism similar to that observed for polysaccharides (e.g., starch, xanthan gum). ${ }^{27}$

In the past few years, animal protein consumption has been substantially altered because of animal diseases, cholesterol intake worries, and strong demand for healthy food, along with ethic orientations of denying animal intakes of any kind. ${ }^{28}$ The use of globular proteins from legumes can be an interesting alternative to animal-protein-based foodstuffs. Their high protein level and well-balanced aminoacid composition makes them important sources of protein, with the potential to replace meat and dairy proteins, if necessary. ${ }^{29}$

Besides their nutritional properties, legume proteins have gained additional importance in modern food design as a consequence of their favorable functional properties. ${ }^{30}$ Several vegetable proteins, such as pea protein, have been studied as successful replacements for animal proteins in oil-in-water emulsions, ${ }^{31,32}$ as wells as in foams ${ }^{33,34}$ and gels. $^{35-37}$

In the present work, lutein and phycocyanin were added to oil-in-water pea protein-stabilized emulsions. The authors intended to develop a comprehensive study on the full rheological characterization of these systems, involving transient stress growth experiments and monitoring rheological tests with an optical analysis system, in order to interpret the shear-induced structural modifications induced by these natural pigments.

\section{Materials and methods}

\section{Preparation of oil-in-water emulsions}

Oil-in-water emulsions were prepared with $65 \%(\mathrm{w} / \mathrm{w})$ vegetable oil, $32 \%(\mathrm{w} / \mathrm{w})$ deionized water, and $3 \%(\mathrm{w} / \mathrm{w})$ pea protein isolate (Pisane HD, Cosucra, Belgium). Lutein (FloraGLO $^{\circledR} 20 \%$ liquid in safflower oil; Kemin Foods, Des Moines, IA,USA) and phycocyanin, obtained from Arthrospira maxima (INETI-DER, Lisbon, Portugal), were dissolved in the oil and aqueous phases, respectively, at $0.75 \%$ $(\mathrm{w} / \mathrm{w})$. An emulsion containing both lutein (oil phase) and phycocyanin (aqueous phase) in the same proportion (50 Lut:50 Phyc, w/w) was also prepared, as well as a control emulsion without pigment addition. The protein isolate and the phycocyanin were dispersed in water under magnetic stirring (30 min, room temperature) and emulsification of the oil phase (with dissolved lutein) was carried out at 
13,000 rpm (5 min) using an Ultra Turrax T-25 homogenizer (IKA, Staufen, Germany), as previously reported by Franco et al. $^{38}$ The emulsions were placed in cylindrical glass containers (60 $\mathrm{mm}$ diameter, $45 \mathrm{~mm}$ height) and stored in a refrigerator at $4^{\circ} \mathrm{C}$. No phase separation was visually detected during 3 months.

Droplet size distribution

Droplet size distribution (DSD) measurements were carried out by laser light scattering using a Malvern Mastersizer-X analyzer (Malvern, UK) in the Fourier conformation. Aliquots of emulsions were carefully dispersed step by step, applying gentle agitation in order to disrupt droplet flocs. Values of the Sauter mean diameter, $d_{3,2}$, which is inversely proportional to the specific surface area of droplets, were obtained as follows ${ }^{38}$ :

$d_{3,2}=\frac{\sum n_{i} d_{i}^{3}}{\sum n_{i} d_{i}^{2}}$

where $n_{i}$ is the number of droplets with a diameter $d_{i}$.

\section{Rheological measurements}

Small-amplitude oscillatory shear (SAOS) measurements were carried out inside the linear viscoelastic regime in a frequency range of $0.00628-628 \mathrm{rad} / \mathrm{s}$, using a controlled stress rheometer (RS-75; Haake, Karlsruhe, Germany) with a cone-and-plate sensor system ( $35 \mathrm{~mm}$ diameter, $2^{\circ}$ angle). The linear viscoelastic range was previously determined by performing stress sweep tests at a constant frequency $(6.28 \mathrm{rad} / \mathrm{s})$. Steady-state flow measurements were performed in the RS-75 rheometer in a shear stress range of 0.1-2000 Pa, using a serrated parallel-plate sensor system (20 $\mathrm{mm}$ diameter, $1 \mathrm{~mm}$ gap), which was used to avoid wall-slip phenomena. ${ }^{39}$ Transient shear flow (stress growth) measurements were performed in controlled strain rheometer (ARES, Rheometrics Scientific, Germany), also using a serrated plate-plate geometry ( $25 \mathrm{~mm}$ diameter, $1 \mathrm{~mm}$ gap). Transient stress responses were recorded at different constant shear rates $\left(0.01,0.1,1\right.$, and $\left.10 \mathrm{~s}^{-1}\right)$. All the rheological experiments were repeated, under the same conditions, in a controlled stress rheometer coupled with an optical microscope and digital video camera (RheoScope 1; Haake), in order to monitor the structural modifications that occur during the tests. For these measurements, a cone-andglass-plate geometry (70 mm diameter, $1^{\circ}$ angle) was used. Micrographs obtained with RheoScope ${ }^{\circledR}$ have been presented in this work together with flow measurements obtained with roughened tools. It was intended to present a qualitative interpretation of the microstructure alteration at different shear stress and viscosity ranges, in spite of the possible appearance of wall slip phenomena in the glass plate surface. All rheological measurements were replicated at least three times, $24 \mathrm{~h}$ after emulsions manufacture.

Statistical analysis

ANOVA/MANOVA, post-hoc comparisons-Scheffé test, was performed by using STATISTICA (Version 6.0; Statsoft Inc., Tulsa, OK, USA) to compare and evaluate the significance of the differences on the emulsions' rheological parameters and Sauter mean diameter values (significance level was set at 95\%).

\section{Results and discussion}

The use of lutein and phycocyanin pigments to color oil-inwater pea protein stabilized emulsions promoted significant modifications on their microstructure. The effects were distinct according to the pigment nature, particularly affinity to the aqueous or to the oil phase, and will be discussed on the basis of the rheological behavior observed from the oscillatory, steady-state flow and transient flow tests. The microscope photographs taken during the rheological tests also provided useful information, especially for the control and lutein emulsions that are more fluid, whereas for the emulsions containing phycocyanin and blend of pigments that were very consistent and opaque, it was more difficult to obtain accurate microscopic measurements.

\section{Droplet size distributions}

Figure 1 shows DSD curves for emulsions containing different pigments in comparison to a pigment-free emulsion used as control. As can be observed, DSD are quite similar in all cases. However, values of the Sauter diameter of emulsions containing lutein (in both cases, as the only pigment and blended with phycocyanin) are slightly higher than either the control emulsion or the emulsion containing only phycocyanin as a coloring agent (Figure 1).

\section{Linear viscoelasticity}

The linear viscoelastic regions of the emulsions under study obtained from stress sweep tests are presented in Figure 2. The lutein and control emulsions presented a similar behavior, a gradual decrease on the storage modulus $\left(G^{\prime}\right)$ values after a certain critical strain being observed. For the emulsion containing phycocyanin and both types of pigments, the linear viscoelastic range is more extended $\left(\gamma_{\mathrm{c}} \approx\right.$ $0.10)$ and the storage and loss moduli $\left(G^{\prime}, G^{\prime \prime}\right)$ values are higher. However, starting from this critical strain value, a steep decrease of these functions is observed, more sharply 
Fig. 1. Droplet size distribution curves and respective Sauter mean diameter of $\mathrm{o} / \mathrm{w}$ emulsions without pigment addition (control), with $0.75 \%$ lutein, $0.75 \%$ phycocyanin, and $0.50 \%$ total pigment (lutein and phycocyanin in the same proportion) addition.

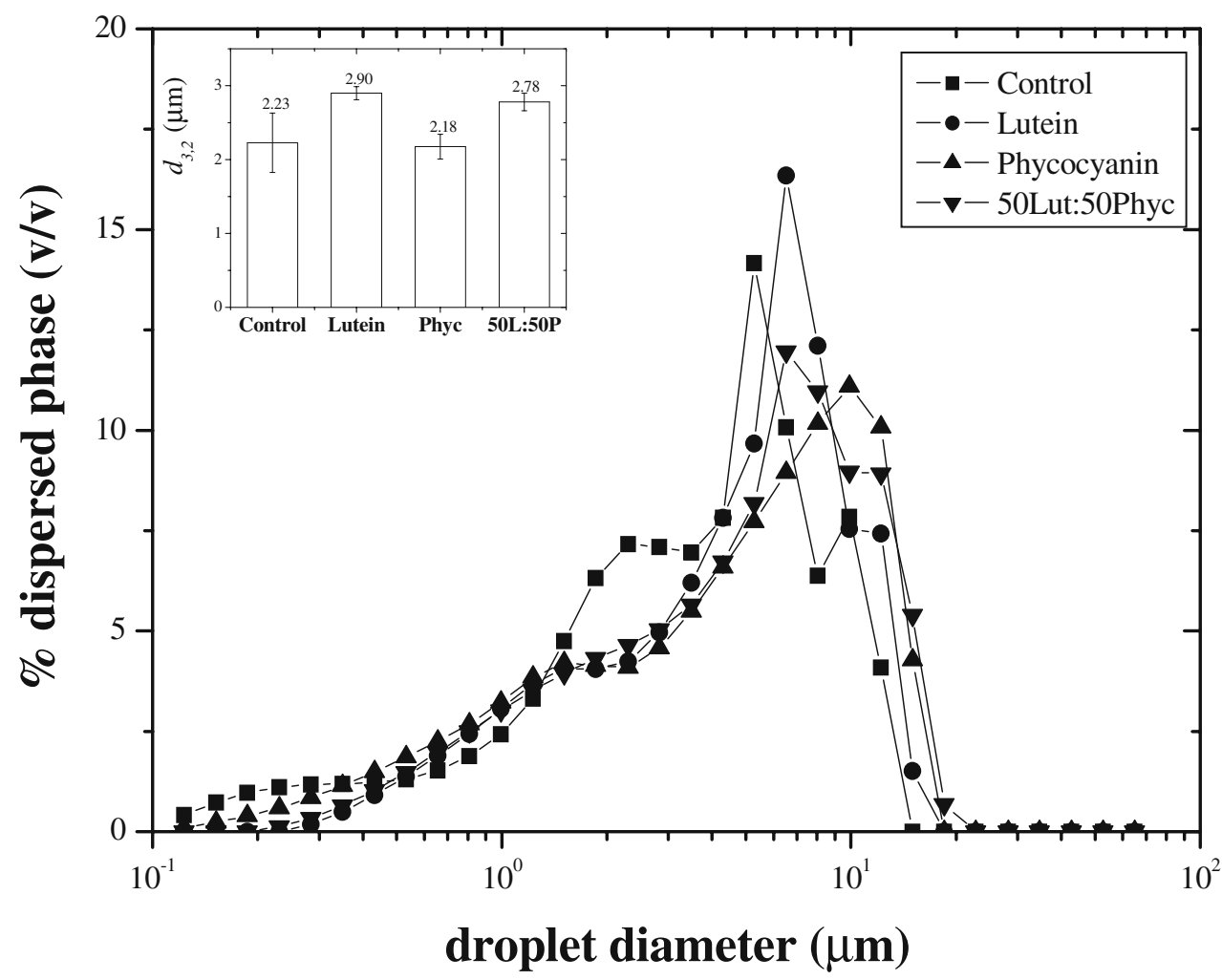

for emulsions containing phycocyanin. Moreover, from the comparison of the microscope images corresponding to strain values of the same order of magnitude (1-10), it is possible to observe a higher structural breakdown for both the phycocyanin and blended emulsions, in which an alteration of the flocculated state is apparent outside the linear viscoelastic regime. In contrast, for both lutein and control emulsions, shear-induced structural modifications are less pronounced by applying the same stress program.

Figure 3 represents the evolution of the storage $\left(G^{\prime}\right)$ and loss $\left(G^{\prime \prime}\right)$ moduli of the emulsions during SAOS measurements, inside the linear viscoelastic region. $G^{\prime}$ was always higher than $G^{\prime \prime}$ within the experimental frequency range. Hence the emulsions present a predominantly elastic response, showing a plateau region with a minimum in $G^{\prime}$ and a slight frequency dependence of $G^{\prime}$. This behavior is typical of protein-stabilized emulsions in which an elastic network develops as a result of the occurrence of an extensive bridging flocculation process. ${ }^{27,38}$ The development of the plateau region has been previously related to the formation of physical entanglements among macromolecules adsorbed and nonadsorbed at the oil/water interface of the oil droplets, yielding a structural network. ${ }^{40}$ The plateau modulus $\left(G_{\mathrm{N}}^{0}\right)$ is a viscoelastic parameter defined for polymers as the extrapolation of the entanglement contribution to the viscoelastic functions at high frequencies. ${ }^{41}$ This parameter can be considered as a characteristic pa- rameter of this region and may be easily estimated from the minimum in the loss tangent $\left(\tan \delta=G^{\prime \prime} / G^{\prime}\right)$ as follows ${ }^{42}$ :

$G_{\mathrm{N}}^{0}=\left[G^{\prime}\right]_{\tan \delta \rightarrow \text { minimum }}$

As shown in Figure 3, the emulsion containing phycocyanin presented significantly $(p<0.05)$ higher values for the viscoelastic functions $\left(G^{\prime}, G^{\prime \prime}\right.$, and $\left.G_{\mathrm{N}}^{0}\right)$ than the control indicating a more developed three-dimensional structure, whereas lutein emulsion presented significantly $(p<0.05)$ smaller values. The emulsion containing both pigments presented an intermediate behavior, similar to the control emulsion.

The microscopic images of the emulsions, taken during SAOS measurements, did not present significant changes because these tests were performed within the linear viscoelastic range of stresses, corresponding to the quasiunperturbed emulsion microstructure. Thus, these photographs - taken along the whole frequency range studiedare very similar to the photographs presented in Figure 2 for the emulsions at low strain values before the onset of the nonlinear viscoelastic region.

Steady-state flow curves

All the emulsions studied showed similar flow curves under steady shear conditions presenting a strong shear-thinning 
a

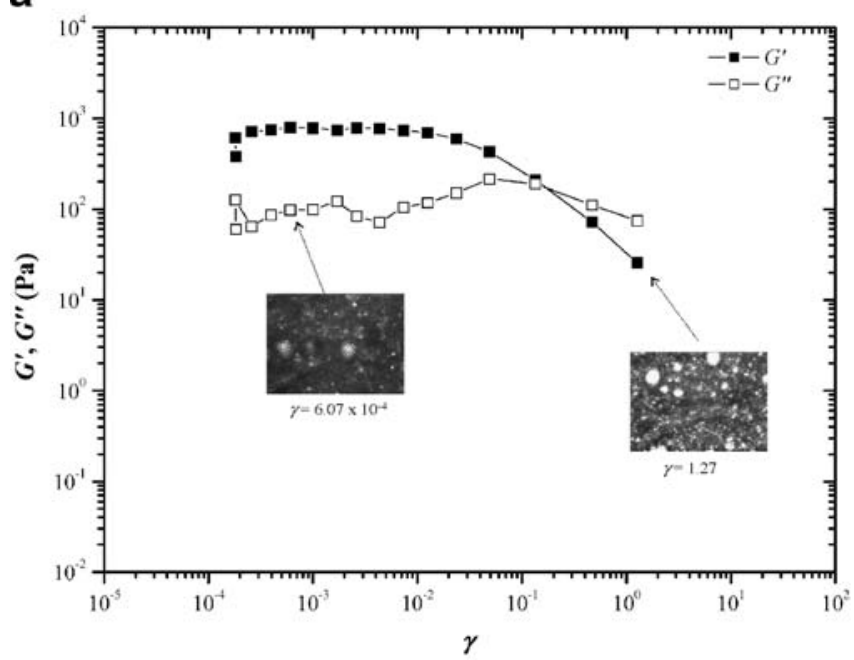

b

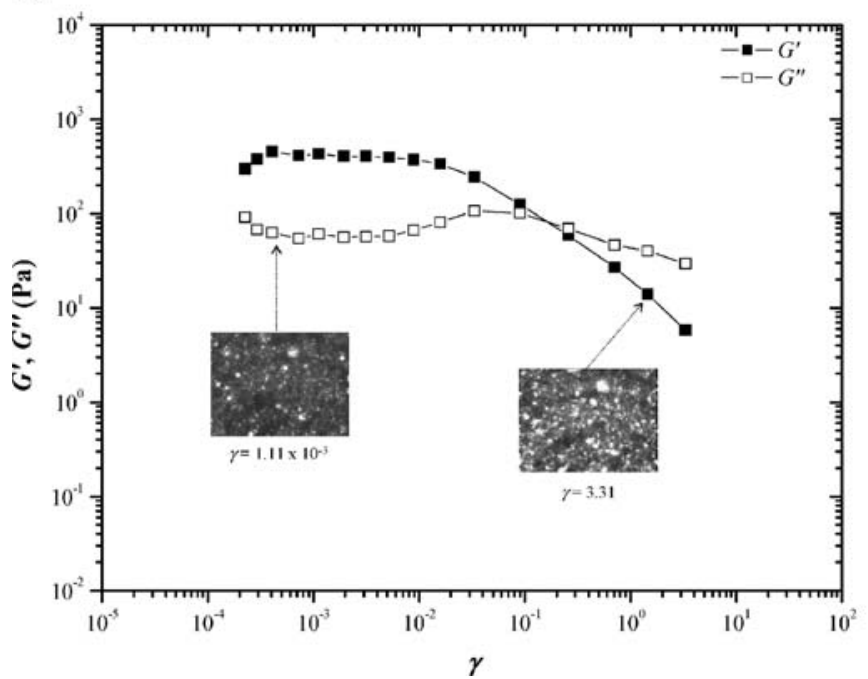

Fig. 2. Linear viscoelastic range of $\mathrm{o} / \mathrm{w}$ pea protein emulsions (a) without pigment addition, (b) with $0.75 \%$ lutein, (c) $0.75 \%$ phycocyanin, and (d) $0.50 \%$ total pigment (lutein and phycocyanin in the same proportion)
C

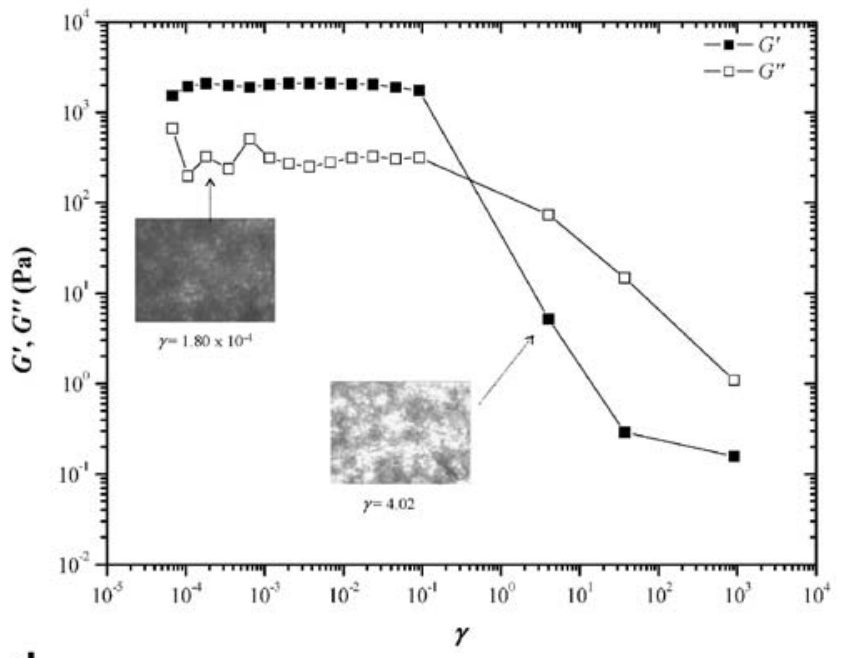

d

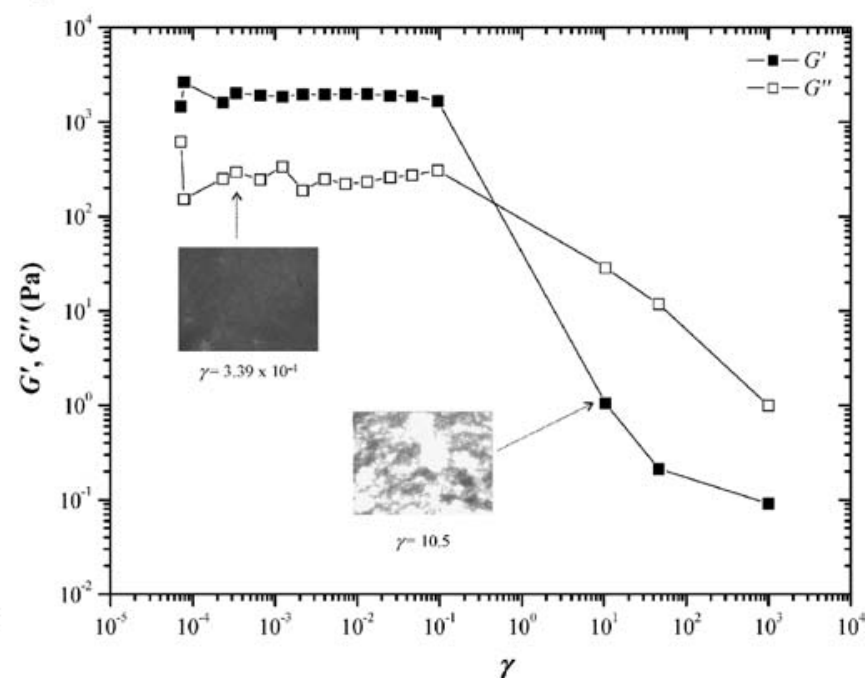

addition. The microscope photographs retrieved by the RheoScope ${ }^{\circledR}$ equipment, represent the emulsions' microstructure changes occurring at different shear values during the test. behavior (Figure 4). At low stress values, these emulsions exhibit a constant high viscosity value $\left(\eta_{0} \approx 10^{5} \mathrm{~Pa} \cdot \mathrm{s}\right)$ that suddenly falls by several orders of magnitude, to a much more fluid behavior. This type of flow was recently well described by Roberts et al., ${ }^{43}$ and it has also been reported for other concentrated food emulsions ${ }^{38,40}$ as a result of a drastic shear-induced structural breakdown, related to a mechanism of entanglement breakdown and oil droplet deflocculation.

Lutein emulsion presented zero shear viscosity values $\left(\eta_{0}\right)$ that were almost 1 order-of-magnitude lower than the control emulsion, evidencing a negative effect of pigment addition on emulsion microstructure, which is in agreement with the results obtained from SAOS measurements. These emulsions' microstructure evolution along the Newtonian and shear-thinning region of stress can be observed in Figures $4 \mathrm{a}-\mathrm{b}$. A progressive shear-induced defloculation process was detected for both emulsions by visualizing different concentric flow regions.

On the other hand, the emulsions containing phycocyanin presented a wider plateau region with significantly $(p<$ $0.05)$ higher $\eta_{0}$ values than the control emulsion. The viscosity decrease at high stress values is much sharper, as a consequence of a dramatic structural breakdown after a critical stress. The same qualitative behavior was observed for the emulsion containing both types of pigments. In spite of this structural breakdown, phycocyanin-based emulsions presented higher viscosity values than the control emulsion at shear stress values studied. As may be seen in the microscope photographs (Figures $4 \mathrm{c}-\mathrm{d}$ ), the microstructure 
Fig. 3. Mechanical spectra and plateau modulus value of $\mathrm{o} / \mathrm{w}$ emulsions without pigment addition (control), with $0.75 \%$ lutein, $0.75 \%$ phycocyanin, and $0.50 \%$ total pigment $(\mathrm{lu}-$ tein and phycocyanin in the same proportion) addition.

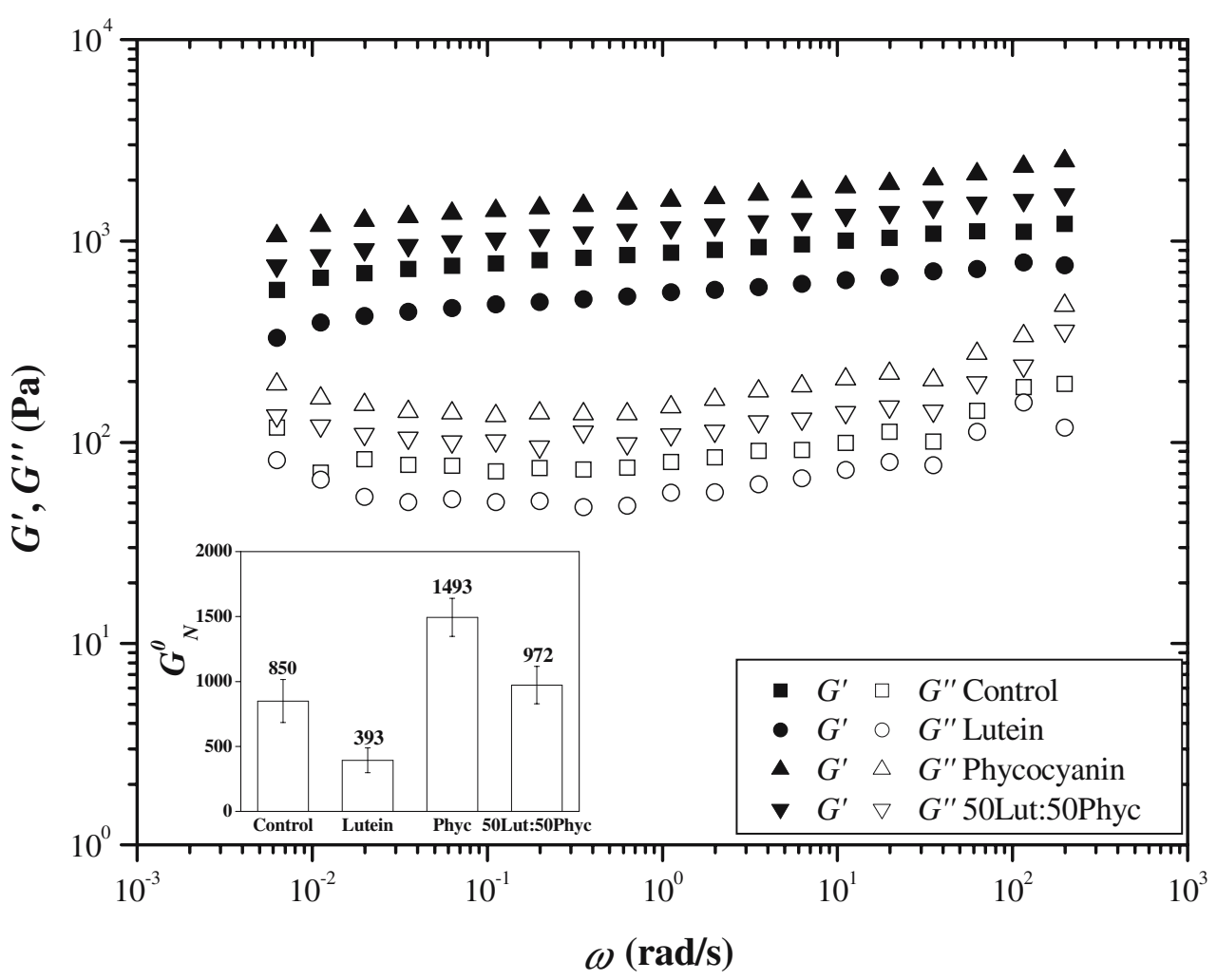

of these two emulsions is not significantly altered prior to the viscosity decrease. However, a structural modification can be observed afterwards. In addition to this, some zones that are not occupied by the sample appear, at very high shear stresses, which are attributed to the beginning of the expulsion of the sample from the gap. These last points and the corresponding micrographs were maintained in Figures $4 \mathrm{c}-\mathrm{d}$, in order to illustrate the phenomenon of fracture and subsequent expulsion of the sample from the gap although it is evident that no physical interpretation may be deduced from that situation.

Steady shear flow viscosity data can be related to dynamic complex viscosity $\left(\eta^{*}\right)$, through the empirical Cox-Merz rule ${ }^{44}$ which states that the complex viscosity is nearly equal to the steady shear viscosity when the shear rate and frequency are equal. This correlation has been experimentally confirmed for several synthetic polymers ${ }^{45}$ and polysaccharide solutions, ${ }^{46}$ but a deviation of the CoxMerz rule has been observed for several food products. ${ }^{47-49}$

Figure 5 presents both steady-state and dynamic viscosity results for the emulsions under study. It was observed that complex viscosity values were higher than steady shear viscosity and that the power law decrease was approximately the same in both types of measurements, as it has been reported for other emulsions, ${ }^{49}$ except for the lutein emulsion. In consideration of this factor, the relative deviation of the Cox-Merz rule $\left(\eta_{\text {rel }}\right)$ was obtained, independently of the frequency or shear rate, as follows:

$\eta_{\mathrm{rel}}=\left.\frac{\eta^{*}-\eta}{\eta^{*}}\right|_{\dot{\gamma}=\omega}$

The emulsions containing phycocyanin and pigment blend showed higher $(p<0.05) \eta_{\text {rel }}$ values $(0.83)$ than the control emulsion (0.795). For the lutein emulsion, the potential decrease on the $\eta=f(\gamma)$ and $\eta^{*}=f(\omega)$ curves was different, so the $\eta_{\text {rel }}$ values varied between 0.87 and 0.95 , being presented in Figure 5 an average value. In any case, the Cox-Merz deviation was always higher than those observed for other emulsions.

The deviation from Cox-Merz rule has been attributed to a structural decay due to the extent of strain applied. By definition, applied strain is low in SAOS measurements, but is high enough in steady shear to break down structured inter- and intramolecular associations. ${ }^{50-52}$ Accordingly, we can consider that the shear-induced structural breakdown in pea protein emulsions increased with pigment incorporation, particularly for lutein.

\section{Transient flow}

The emulsions transient flow behavior was studied by stress growth experiments, in which a constant shear rate is 

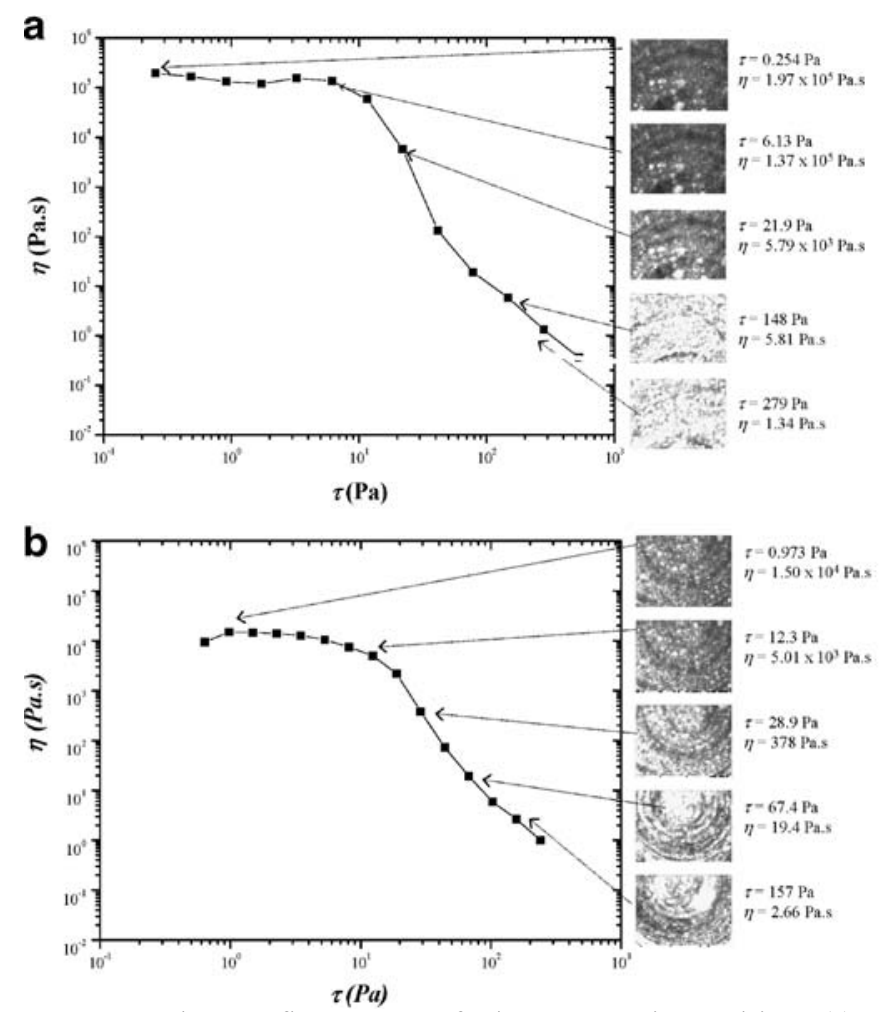

Fig. 4. Steady-state flow curves of $\mathrm{o} / \mathrm{w}$ pea protein emulsions (a) without pigment addition, (b) with $0.75 \%$ lutein, (c) $0.75 \%$ phycocyanin, and (d) $0.50 \%$ total pigment (lutein and phycocyanin in the same

suddenly imposed on a viscoelastic fluid held previously at rest ("start-up flow"). ${ }^{53}$ The evolution of the emulsions transient stress during these tests, at different shear rate values $\left(0.01,0.1,1\right.$, and $\left.10 \mathrm{~s}^{-1}\right)$, can be observed in Figure 6.

All the emulsions studied presented a characteristic viscoelastic behavior with two distinct regions in the time dependency curves, as it has been observed in other food emulsions. ${ }^{51,54,55}$ At relatively short times, the onset of shear originates a sudden stress overshoot $\left(\tau_{\text {overshoot }}\right)$ that corresponds to the viscoelastic response of the material. After reaching this maximum, the shear stress decays to an almost constant (steady-state) equilibrium value $\left(\tau_{\infty}\right)$ at long times, as a result of time-dependent shear-induced structural modifications. ${ }^{56}$ From the curves in Figure 6, we can clearly observe that characteristic times and stresses are dependent on the applied shear rate and emulsion composition.

The Leider-Bird Model ${ }^{57}$ was shown to be adequate in describing the transient behavior of several food products, ${ }^{58,59}$ and it was used to fit the emulsions stress growth curves in its generalized form ${ }^{56}$ with three exponential terms:

$\tau=\tau_{\infty}\left[1+(b \dot{\gamma} t-1) \sum_{j=1}^{3} w_{j} \mathrm{e}^{\left(-t / \lambda_{j}\right)}\right]$
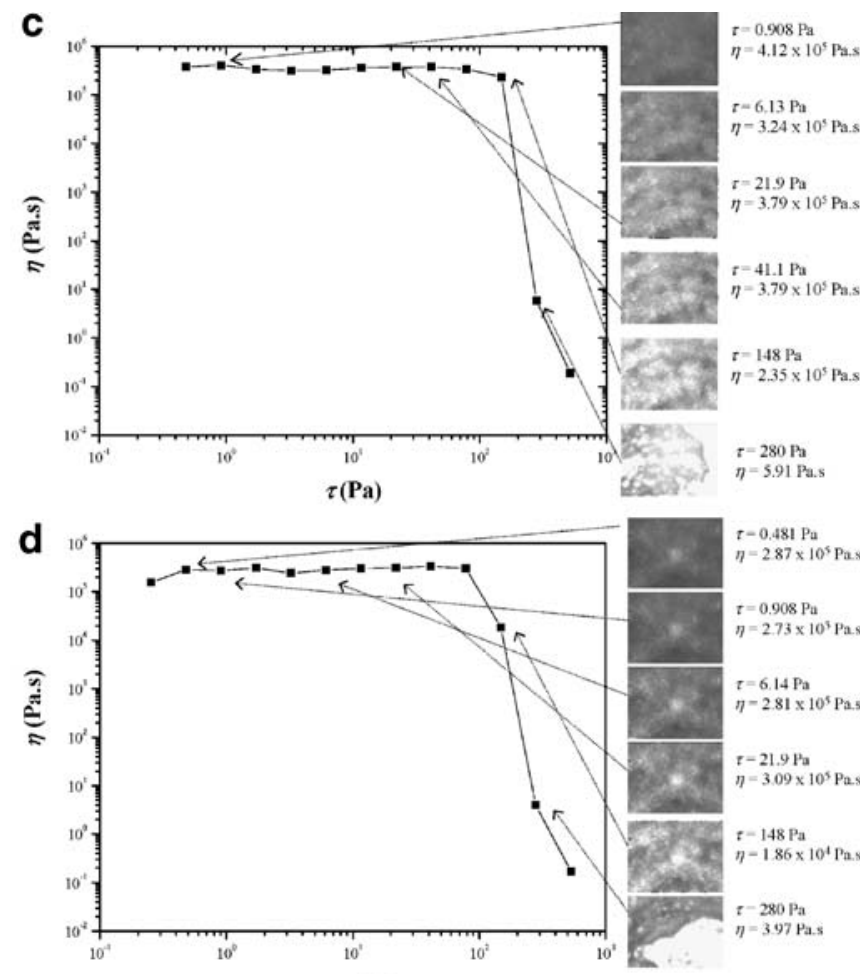

$\tau(\mathrm{Pa})$

proportion) addition. The microscope photographs retrieved by the RheoScope ${ }^{\circledR}$ equipment, represent the emulsions' microstructure changes occurring at different stress values during the test.

where $\tau_{\infty}$ is the equilibrium shear stress, $b$ is a fitting parameter related to the absolute values of transient stress, $w_{j}$ are the fitting parameters that assign relative weights to the exponential terms, and $\lambda_{j}$ are the time constants. The LeiderBird equation fitted the experimental results quite well (Figure 6), with determination coefficients $\left(R^{2}\right)$ greater than 0.97 and reduced chi-square values $\left(\chi^{2}\right)$ smaller than 10 for all the curves analyzed.

Figure 7 collects more relevant parameters of stressgrowth curves deduced from Eq. (4). Figure 7a shows the emulsion equilibrium shear stress values, obtained at different shear rates. The emulsions containing phycocyanin (isolated and blended) showed higher values than the control emulsion, in contrast to that found with lutein-based emulsions, which is in concordance with the results previously shown. As may be observed, almost constant values of $\tau_{\infty}$ were attained in all cases, because the shear rate range corresponds to the drastic viscosity decrease seen in Figure 4.

Time for the overshoot $\left(t_{\max }\right)$ was deduced by deriving Eq. (4) with respect to time and making this derivative equal to zero. The value of the stress overshoot was then obtained by substituting $t_{\max }$ in Eq. (4). Stress overshoot values follow the same tendency with pigment addition than that described by $\tau_{\infty}$ (Figure $7 \mathrm{~b}$ ). The structural 
Fig. 5. Comparison between steady-state and complex viscosities and relative deviation of the Cox-Merz rule for o/w pea protein emulsions without pigment addition (control), with $0.75 \%$ lutein, $0.75 \%$ phycocyanin, and $0.50 \%$ total pigment (lutein and phycocyanin in the same proportion) addition.

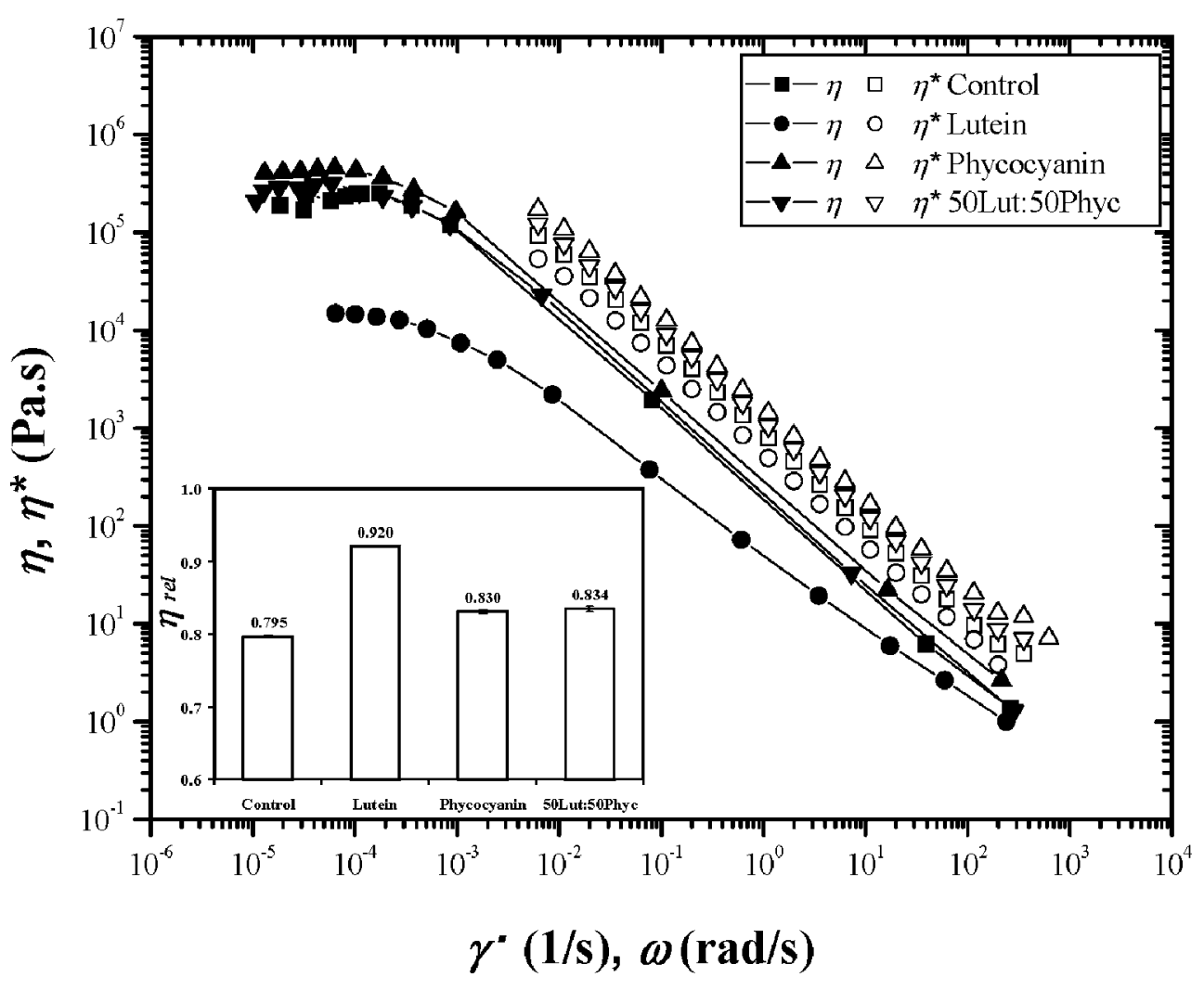

breakdown was faster for the control emulsion, which presented the stress overshoot at shorter times (Figure 7c), indicating that the addition of pigments induces structural networks that are able to resist higher deformations. For all emulsions, a slight linear increase on stress overshoot and a linear decrease on time overshoot with shear rate were observed.

The amount of overshoot (relative peak height) is a parameter related to the viscoelastic response and the degree of structural breakdown occurring in the system at constant shear rate, and is defined as ${ }^{56}$ :

$S^{+}=\frac{\tau_{\max }-\tau_{\infty}}{\tau_{\infty}}$

In general, the introduction of phycocyanin (isolate or blended) in pea protein-stabilized emulsions resulted in a higher amount of overshoot (Figure 7d), as compared with the control emulsion, which confirms the results shown in Figure 5. With respect to lutein addition, at low shear rates $\left(0.01-0.1 \mathrm{~s}^{-1}\right)$ the relative overshoot peak height was lower than the control emulsion, whereas at higher shear rates (1$10 \mathrm{~s}^{-1}$ ) it suddenly increased to considerably higher values than for the other emulsions, as also observed for $\eta_{\text {rel }}$ (Figure 5).

The transient tests were repeated on the RheoScope ${ }^{\circledR}$ in order to monitor the resulting time-dependent structural changes in the emulsions with optical system. Figure 8 shows the images obtained for the lutein emulsion, at $1 \mathrm{~s}^{-1}$ shear rate, taken before, during, and after the overshoot (that occurred at different times and stresses). We can clearly observe the structural breakdown taking place as the stress overshoot is reached, and that the deformation attained is not recovered. Once again, this microphotograph evidences that a significant structural modification takes place when the viscous response is predominant over the elastic one.

Structural considerations

The incorporation of lutein and phycocyanin imparted relevant modifications on the structural and rheological properties of oil-in-water pea protein emulsions, which may be related with different DSD, changes on the rheology of the bulk continuous phase or to specific molecular interactions at the interface.

In general, lutein emulsion presented lower rheological properties than the control emulsion. This is in agreement with DSD results (Figure 1) where a significant $(p<0.05)$ increase in the Sauter mean diameter with lutein addition $(0.75 \%$ and $50 \mathrm{~L} / 50 \mathrm{P})$ was observed. Moreover, the lutein emulsion generally presented a higher shear-induced structural breakdown than the other emulsions studied. 
a

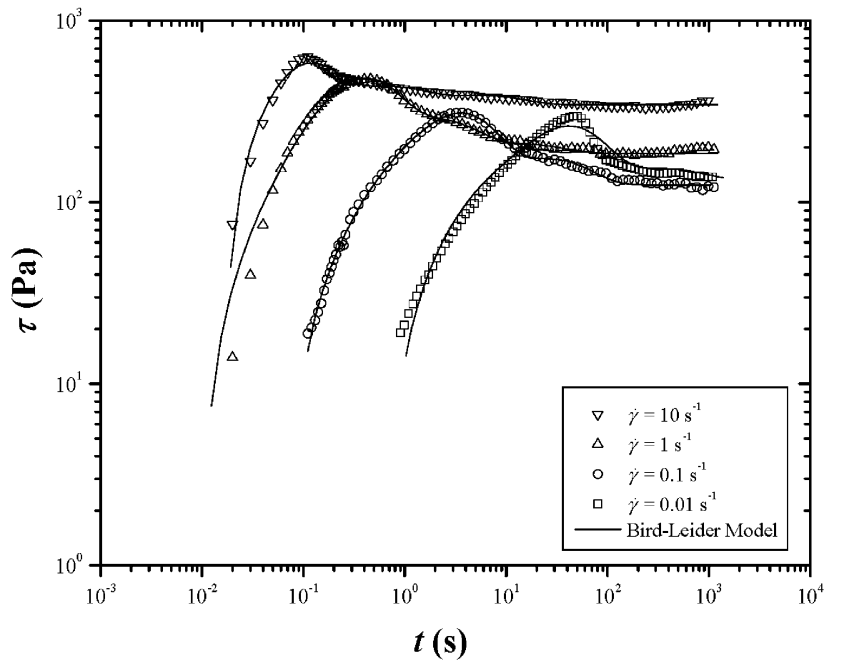

b

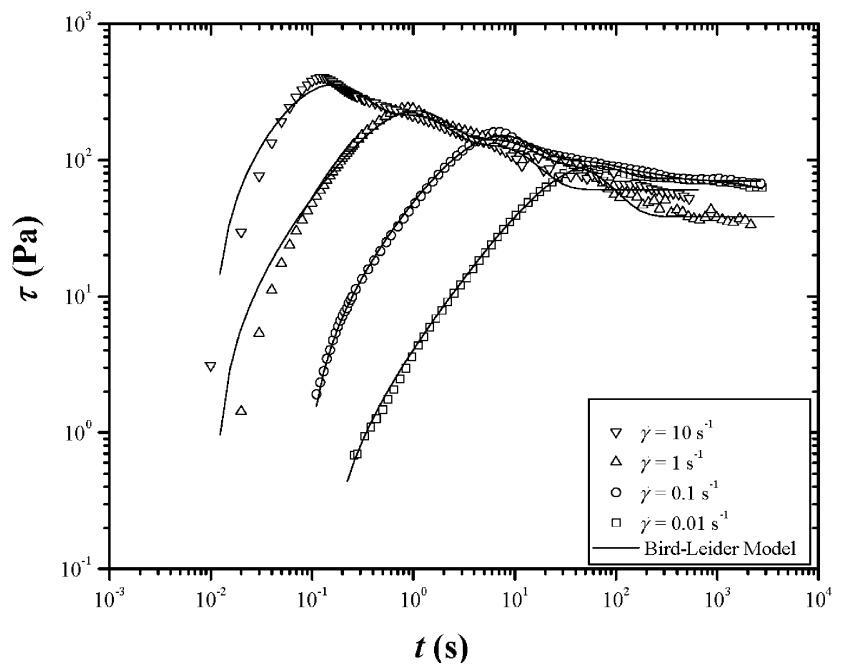

Fig. 6. Stress growth experiments at constant shear rates $(0.01,0.1,1$, and $10 \mathrm{~s}^{-1}$ ) and Leider-Bird model fitting for $\mathrm{o} / \mathrm{w}$ pea protein emulsions (a) without pigment addition (control), (b) with $0.75 \%$

Adding lutein to the oil fraction could have modified the nature of the emulsions' dispersed phase, namely, the strength of the attractive interactions between molecules and the effectiveness of their packing in the condensed phase. ${ }^{26}$ Recent studies ${ }^{6,60}$ : have suggested that not only the surfactant molecules, i.e., emulsifiers and proteins, but also the fat used in the emulsions formulation participates in the development of the interface characteristics and rheological properties. Moreover, it is well known that globular proteins exhibit hydrophobic domains that may also interact with the oil phase. This can be particularly relevant if we consider that lutein molecules are mainly lipophylic molecules but present polar hydroxyl groups in both ends of the conjugated polyisoprenoid chain. Accordingly, we can suppose that lutein molecules located inside
C

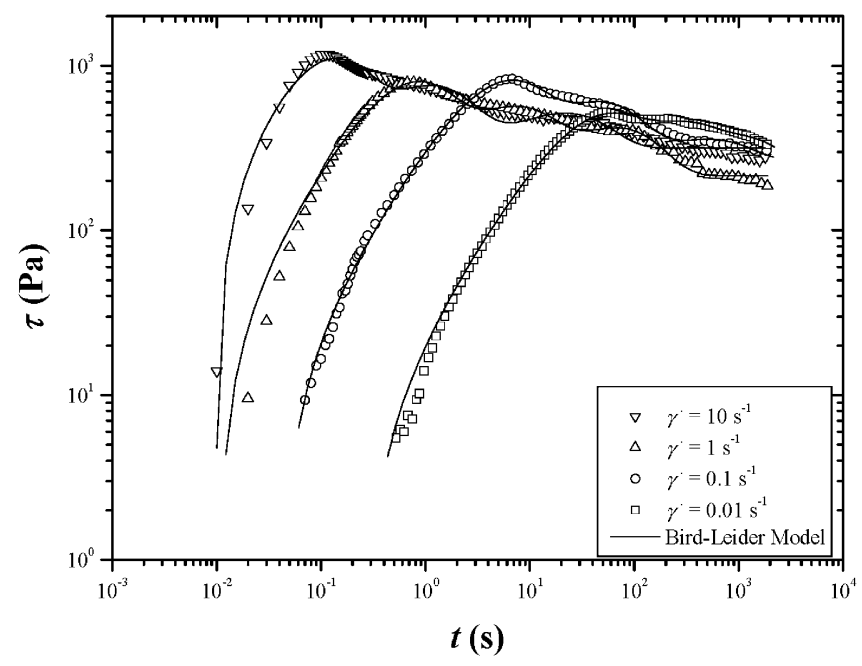

d

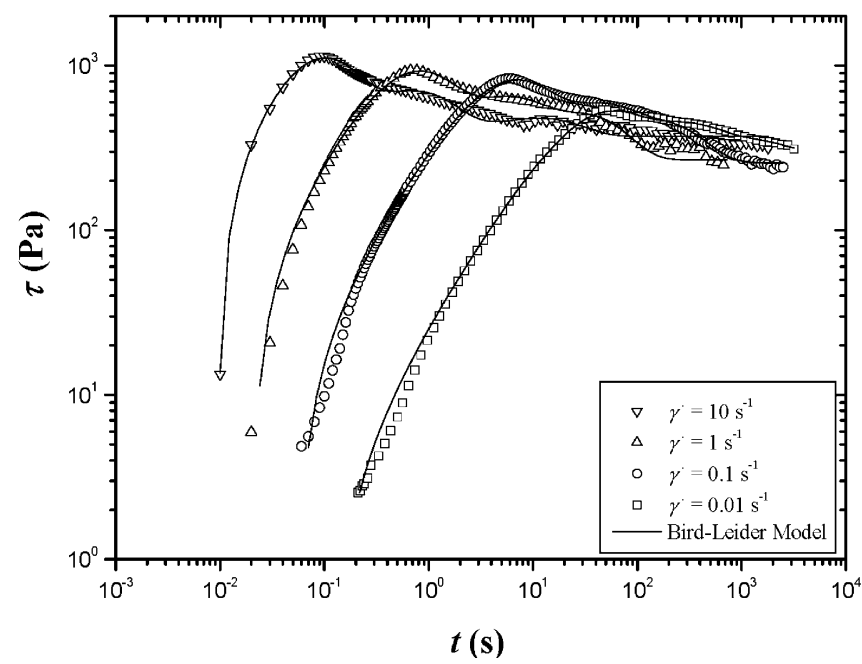

lutein, (c) $0.75 \%$ phycocyanin, and (d) $0.50 \%$ total pigment (lutein and phycocyanin in the same proportion) addition.

oil droplets could penetrate in the interface, interacting with pea protein creating weaker and disordered layers, thereby resulting in higher droplet mean diameters and poor rheological properties.

The addition of phycocyanin resulted in a significant improvement of the emulsions rheological properties. The emulsion structure was clearly reinforced, there being observed a higher resistance to structural breakdown, occurring at higher stress or shear rate values. Hence, a dramatic decrease in rheological characteristics is observed upon the onset nonlinear viscoelastic stresses and on steady-state shear flow curves (confirmed by RheoScope ${ }^{\circledR}$ images), as well as by the relative deviation of Cox-Merz rule and transient shear growth tests results. No significant $(p<0.05)$ differences were found between the control and phycocy- 

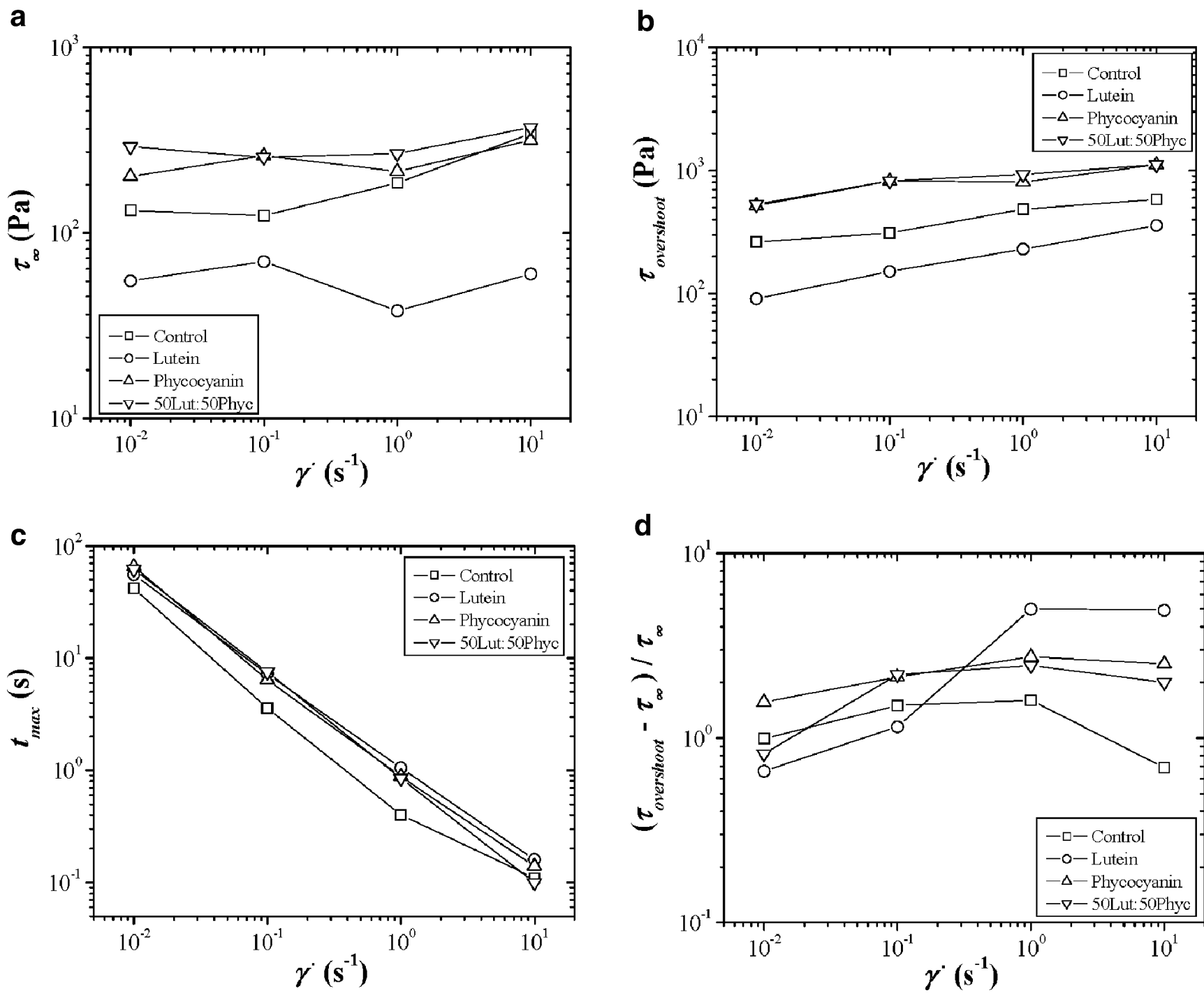

Fig. 7. Equilibrium shear stress $\tau_{\infty}$ (a), stress overshoot $\tau_{\max }$ (b), time for the overshoot $t_{\max }(\mathrm{c})$, and amount of overshoot $S^{+}$(d) for o/w pea protein emulsions without pigment addition (control), with $0.75 \%$

anin emulsions Sauter mean diameters (Figure 8) at $0.75 \%$ (w/w) concentration, which corresponds to the minimum mean droplet size found in previous studies ${ }^{61}$ with various phycocyanin incorporation levels.

The presence of phycocyanin protein molecules may have contributed to a marked increase in the viscosity of the aqueous continuous phase, thus retarding the oil droplet association movements and consequently enhancing emulsion stability. The formation of an entangled three-dimensional network between phycocyanin protein molecules and pea protein could explain the difficulty in obtaining accurate RheoScope ${ }^{\circledR}$ images, which present major differences from the control and lutein emulsions. It is also possible that phycocyanin protein molecules interact in the interfacial protein adsorbed layer at the surface of oil

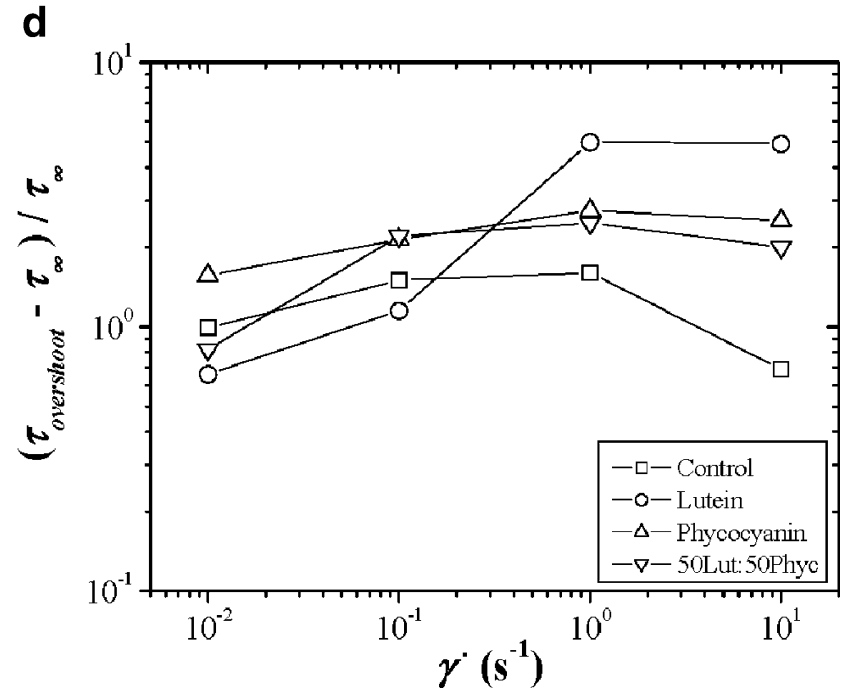

lutein, $0.75 \%$ phycocyanin, and $0.50 \%$ total pigment (lutein and phycocyanin in the same proportion) addition.

droplets, reinforcing in this case the pea protein emulsifier film and imparting stability to emulsions. In previous studies, ${ }^{25}$ it was demonstrated that a protein isolate from blue-green algae (Spirulina platensis strain Pacifica), containing phycocyanin, was capable of reducing the interfacial tension at the aqueous/air interface at relatively lower bulk concentrations, compared to common food proteins.

The overall characteristics of the emulsion containing lutein and phycocyanin results from a combination of the effects observed for the emulsions containing each pigment individually. Rheological properties are intermediate between lutein and phycocyanin emulsions. In contrast to some results obtained in previous studies for higher phycocyanin/ lutein ratios, ${ }^{61}$ we did not observe a synergistic effect between both pigments. The phycocyanin proportion 
Fig. 8. Microscope photographs of an $\mathrm{o} / \mathrm{w}$ pea protein emulsion with $0.75 \%$ lutein, retrieved by the RheoScope ${ }^{\circledR}$ equipment during a stress growth experiment at constant shear rate $\left(1 \mathrm{~s}^{-1}\right)$ (a) before stress overshoot, (b) during and immediately after stress overshoot, and (c) at equilibrium time.

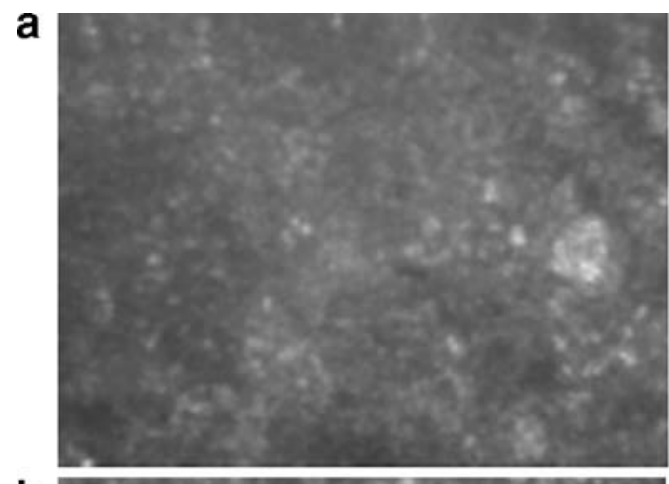

b
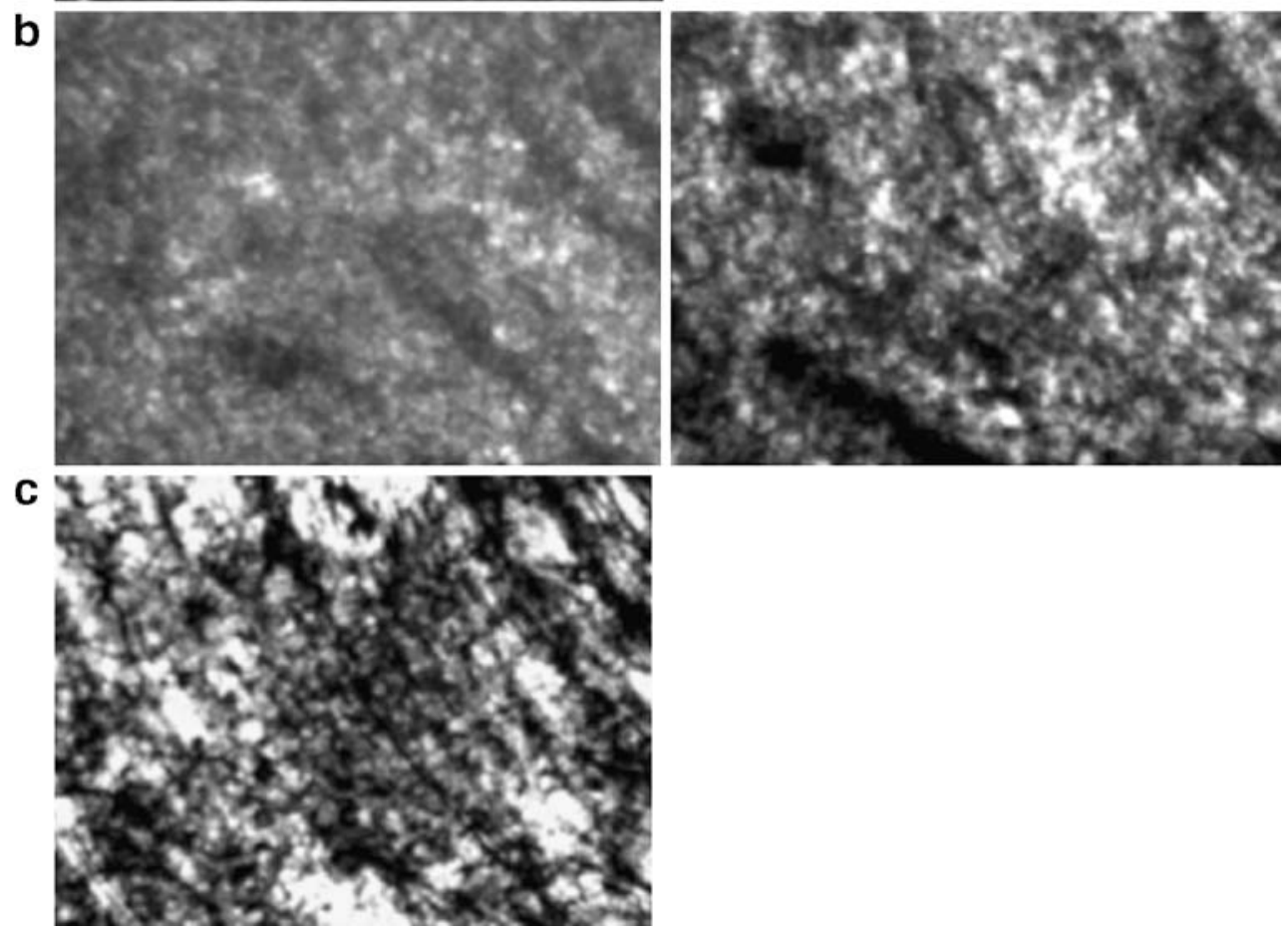

imparted an improved structural resistance to shear stress, evidenced by the stress growth results, by the shape of steady-state flow and stress sweep curves, and also confirmed by the RheoScope ${ }^{\circledR}$ microscope images, which are similar to the phycocyanin emulsion. However, the Sauter mean diameter (Figure 1) is significantly higher $(p<$ $0.05)$ than the control emulsion, which should be related with its lutein content.

The microstructural evolution of the emulsions monitored by the RheoScope ${ }^{\circledR}$ equipment did not evidence any clear trends, but it was possible to obtain a qualitative evaluation of the main differences between emulsions and the structural modifications induced by rheological tests. To allow the capture of microscopic images by the optical system, it was necessary to use a cone-and-glass-plate system. Therefore, in some photos at high shear rates partial sample exclusion from the gap or wall slip of the sample seemed to occur, which corresponded to erroneous rheological data. Considering this effect, the rheological parameters presented in this paper correspond to the results obtained with serrated plate-plate geometries that are able to avoid these slip effects. $^{39}$

\section{Conclusions}

Lutein and phycocyanin imparted appealing and innovative colorations to food emulsions. However, the addition of these pigments had significant implications on the emulsions' structural and rheological properties. The effects were markedly different for the two pigments used. Their distribution between the continuous (aqueous) and dispersed (oil) phases and its interactions with the emulsifier molecules at the interface seems to be of major importance. The emulsions containing phycocyanin presented significantly higher values for the viscous and viscoelastic parameters analyzed than the control emulsion. The addition of lutein had a negative impact on the emulsion micro 
structure and rheological characteristics, whereas phycocyanin emulsion was clearly reinforced, presenting higher resistance to structural breakdown. An emulsion containing both pigments (in similar proportions) presented an intermediate rheological behavior resulting from a combination of the effects observed for the emulsions containing each pigment individually.

Acknowledgments The authors thank Dr. Alberto Reis (INETIDER) for the phycocyanin production, Kemin and Cosucra for providing the lutein and pea protein isolate samples, and Dias de Sousa, S.A. for permitting the use of the Malvern Mastersizer equipment. A.P. Batista acknowledges the research grant SFRH/BD/ 21388/2005 from Fundação para a Ciência e a Tecnologia.

\section{References}

1. G. Guhr and P. Lachance, In: Nutraceuticals Designer Foods III (Food and Nutrition Press Inc., Trambell, US 1998), p. 311.

2. A. Downham and P. Collins, Int J Food Sci Technol 35, 5 (2000).

3. N. Garti, Colloids Surf A 152, 125 (1999).

4. E. Dickinson, In: Food Polysaccharides and Their Applications, edited by A.M. Stephen (Marcel Dekker, New York 1995).

5. N. Neirynck, P. Van der Meeren, S. Bayarri Gorbe, S. Dierckx and K. Dewettinck, Food Hydrocoll 18, 949 (2004).

6. C. Granger, P. Barey, N. Combe, P. Veschambre and M. Cansell, Colloids Surf B 32, 353 (2003).

7. E. Dickinson, Food Hydrocoll 17, 25 (2003).

8. U. Klinkesorn, P. Sophanodora, P. Chinachoti and D.J. McClements, Food Res Int 37, 851 (2004).

9. D.C. Clark, P.J. Wilde, D.R. Wilson and R. Wustneck, Food Hydrocoll 6, 173 (1992).

10. M.A. Riscardo, J.M. Franco and C. Gallegos, Food Sci Technol Int 9, 53 (2003).

11. A. Raymundo, L. Gouveia, A.P. Batista, J. Empis and I. Sousa, Food Res Int 38, 961 (2005).

12. A. Alves-Rodrigues and A. Shao, Toxicol Lett 150, 57 (2004).

13. H.S. Ribeiro, K. Ax and H. Schubert, J Food Sci 68(9), 2730 (2003).

14. A. Spernath, A. Yaghmur, A. Aserin, R.E. Hoffman and N. Garti, J Agric Food Chem 50, 6917 (2002).

15. H.S. Ribeiro, L.G. Rico, G.G. Badolato and H. Schubert, J Food Sci 70(2), E117 (2005).

16. I. Amar, A. Aserin and N. Garti, Colloids Surf B 33, 143 (2004).

17. J.N. Losso, A. Khachatryan, M. Ogawa, J.S. Godber and F. Shih, Food Chem 92, 737 (2005)

18. A. Khachatryan, Random centroid optimization of lutein-enriched oil in water emulsion at acidic pH, Master of Science Thesis (Graduate Faculty of the Louisiana State University and Agricultural and Mechanical College, USA 2003).

19. A. Shibata, Y. Kiba, N. Akati, K. Fukuzawa and H. Terada, Chem Phys Lipids 113, 11 (2001).

20. R. Bassi, B. Pineau, P. Dainese and J. Marquardt, Eur J Biochem 212, 297 (1993).

21. E.E. Moros, D. Darnoko, M. Cheryan, E.G. Perkins and J. Jerrel, J Agric Food Chem 50, 5787 (2002).

22. C.H. Romay, R. Gonzalez, N. Ledon, D. Remirez and V. Rimbau, Curr Protein Pept Sc 4, 207 (2003).

23. R. Bermejo, E.M. Talavera, C. Valle and J.M. Alvarez-Pez, Colloids Surface B 18, 51 (2000).
24. R. Bermejo, D.J. Tobaruela, E.M. Talavera, A. Orte and J.M. Alvarez-Pez, J Colloid Interf Sci 263, 616 (2003).

25. I.S. Chronakis, A.N. Galatanu, T. Nylander and B. Lindman, Colloids Surf A 173, 181 (2000).

26. D.J. McClements, Food Emulsions: Principles, Practice and Techniques (CRC Press, London 1999).

27. A. Raymundo, J.M. Franco, J. Empis and I. Sousa, JAOCS 79, 783 (2002)

28. H. Bollinger, Food Marketing Techn 15, 10 (2001).

29. T. Vliet, A.H. Martin and M.A. Bos, Curr Opinion Colloid Interf Sci 7, 462 (2002).

30. V.B. Tolstoguzov, In: Functional Properties of Food Macromolecules, edited by S.E. Hill, D.A. Ledward and J.R. Mitchell (Aspen, USA 1998).

31. J.M. Franco, P. Partal, D. Ruiz-Marquez, B. Conde and C. Gallegos, JAOCS 77, 972 (2000)

32. S. Tomoskozi, R. Lasztity, R. Haraszi and O. Baticz, Nahrung 45, 399 (2001)

33. A. Raymundo, J. Empis and I. Sousa, J Food Eng 36, 445 (1998).

34. J. Gueguen, Industrial Proteins 8, 6 (2000).

35. M.C. Nunes, P. Batista, A. Raymundo, M.M. Alves and I. Sousa, Colloids Surf B 31, 21 (2003).

36. A.P. Batista, C.A.M. Portugal, I. Sousa, J.G. Crespo and A. Raymundo, Int J Biol Macromol 36(3), 135 (2005).

37. M.C. Nunes, A. Raymundo and I. Sousa, Food Hydrocoll 20, 106 (2006).

38. J. Franco, A. Raymundo, I. Sousa and C. Gallegos, J Agric Food Chem 46, 3109 (1998).

39. J.M. Franco, C. Gallegos and H.A. Barnes, J Food Eng 36, 89 (1998).

40. J.M. Franco, A. Guerrero and C. Gallegos, Rheol Acta 34, 513 (1995).

41. M. Baumgaertel, M.E. Rosa, J. Machado, M. Masse and H.H. Winter, Rheol Acta 31, 75 (1992).

42. S. Wu, J Polym Sci 27, 723 (1989).

43. G.P. Roberts, H.A. Barnes and P. Carew, Chem Eng Sci 56, 5617 (2001).

44. W.P. Cox and E.H. Merz, J Polym Sci 28, 619 (1958).

45. J.D. Ferry, Viscoelastic Properties of Polymers (John Wiley \& Sons, New York 1980).

46. J.A.L. Silva and M.A. Rao, In: Viscoelastic Properties of Food, edited by A.M. Rao and J.F. Steffe (Elsevier, England 1992).

47. B.L. Bistany and J.L. Kokini, J Texture Stud 12, 287 (1983).

48. M.A. Rao and H.J. Cooley, J Texture Stud 23, 415 (1992).

49. M.A. Riscardo, J.E. Moros, J.M. Franco and C. Gallegos, Eur Food Res Technol 220, 380 (2005).

50. P.L. Mills and J.L. Kokini, J Food Sci 49, 1 (1984).

51. J.M. Franco, M. Berjano, A. Guerrero, J. Munoz and C. Gallegos, Food Hydrocoll 9, 111 (1995).

52. S. Gunasekaran and M.M. Ak, Trends Food Sci Technol 11, 115 (2000).

53. J.F. Steffe, Rheological Methods in Food Process Engineering (Freeman, USA 1992).

54. O.H. Campanella and M. Peleg, J Rheol 31, 439 (1987).

55. P. Partal, A. Guerrero, M. Berjano and C. Gallegos, J Food Eng 41, 33 (1999).

56. A.S. Navarro, C. Ferrero and N.E. Zaritzky, J Texture Stud 30, 43 (1999).

57. P.J. Leider and R.B. Bird, Ind Eng Chem Fundam 13, 336 (1974).

58. J.L. Kokini and A. Dickie, J Texture Stud 12, 539 (1981).

59. A.M. Dickie and J.L. Kokini, J Food Proc Eng 5, 157 (1982).

60. V. Rampon, C. Brossard, N. Mouhous-Riou, B. Bousseau, G. Llamas and C. Genot, Adv Colloid Interface Sci 108-109, 87 (2004).

61. A.P. Batista, A. Raymundo, I. Sousa and J. Empis, Food Hydrocoll 20, 44 (2006). 